\title{
Investigation of dominant hydrological processes in a tropical catchment in a monsoonal climate via the downward approach
}

\author{
L. Montanari ${ }^{1}$, M. Sivapalan ${ }^{2, *}$, and A. Montanari ${ }^{1}$ \\ ${ }^{1}$ DISTART, Faculty of Engineering, University of Bologna, Viale Risorgimento 2, 40136 Bologna, Italy \\ ${ }^{2}$ Departments of Geography and Civil \& Environmental Engineering, University of Illinois at Urbana-Champaign, 220 \\ Davenport Hall, 607 S. Mathews Avenue, Urbana, IL 61801, USA \\ * formerly at: Centre for Water Research, The University of Western Australia, 35 Stirling Highway, Crawley WA 6009, \\ Australia
}

Received: 24 November 2005 - Published in Hydrol. Earth Syst. Sci. Discuss.: 20 February 2006

Revised: 25 July 2006 - Accepted: 15 September 2006 - Published: 19 October 2006

\begin{abstract}
This study explores the dominant processes that may be responsible for the observed streamflow response in Seventeen Mile Creek, a tropical catchment located in a monsoonal climate in Northern Territory, Australia. The hydrology of this vast region of Australia is poorly understood due to the low level of information and gauging that are available. Any insights that can be gained from the few well gauged catchments that do exist can be valuable for predictions and water resource assessments in other poorly gauged or ungauged catchments in the region. To this end, the available rainfall and runoff data from Seventeen Mile Creek catchment are analyzed through the systematic and progressive development and testing of rainfall-runoff models of increasing complexity, by following the "downward" or "top-down" approach. This procedure resulted in a multiple bucket model (4 buckets in parallel). Modelling results suggest that the catchment's soils and the landscape in general have a high storage capacity, generating a significant fraction of delayed runoff, whereas saturation excess overland flow occurs only after heavy rainfall events. The sensitivity analyses carried out with the model with regard to soil depth and temporal rainfall variability revealed that total runoff from the catchment is more sensitive to rainfall variations than to soil depth variations, whereas the partitioning into individual components of runoff appears to be more influenced by soil depth variations. The catchment exhibits considerable inter-annual variability in runoff volumes and the greatest determinant of this variability turns out to be the seasonality of the climate, the timing of the wet season, and temporal patterns of the rainfall. The water balance is also affected by the underlying geology, nature of the soils and the landforms, and the type, density and dynamics of vegetation, although information pertaining to these is lacking.
\end{abstract}

Correspondence to: L. Montanari

(lmontanari@arpa.emr.it)

\section{Introduction}

Recent research has begun to address the urgent need for accurate streamflow reconstructions in order to help sustainable environmental management, and to provide basic information to projects designed to prevent and control natural disasters such as floods and droughts. Unfortunately, catchments in many parts of the world are ungauged or poorly gauged, and the dominant processes governing their streamflow response are still poorly understood. It is well known that the present generation of hydrologic models to predict streamflow responses or to estimate peak river discharges in poorly gauged or ungauged catchments suffer from considerable approximations due to uncertainties in the climatic inputs, in model parameters and especially in understanding of the underlying and dominant processes. Recognizing this, the International Association of Hydrological Sciences (IAHS) has recently launched the International Decade on Prediction in Ungauged Basins, the PUB initiative (Sivapalan et al., 2003a). One of the research aims of PUB is to develop new or improved methodologies for making inferences about the hydrological behaviour in ungauged catchments, on the basis of available knowledge and understanding available at the local and regional scales. Tropical regions are some of the most difficult and least understood areas of the world in terms of every one of these sources of uncertainties - this paper is a contribution towards greater understanding of the hydrology of tropical catchments through the development and implementation of hydrological models that are sufficient to capture the dominant processes and their interactions appropriate to this region.

Under conditions of inadequate or incomplete data availability the application of complex models that require extensive calibration is often not advisable. In fact, the application of models consisting of a large number of parameters often suffer from structural arbitrariness and over-parameterization

Published by Copernicus GmbH on behalf of the European Geosciences Union. 
(Klemes, 1983), leading to the problem of equifinality (Beven, 2002, 2006). Indeed, the estimation of parameters belonging to complex models having little or no physical meaning often leads to considerable uncertainty.

There has been an intense debate about advantages and disadvantages of physically based and conceptual models (see, for instance, Beven, 1989; Bathurst, 1992; O’Connell and Todini, 1996; Reggiani et al., 1998; Klemes, 1983). Current physically based models represent an upward or reductionist approach (Sivapalan and Young, 2005) to model development in that the total catchment behaviour is expressed in terms of mathematical representation of physical laws and hydrological theories that are applicable at small scales (Blöschl and Sivapalan, 1995). This approach has a number of drawbacks with regard to application to ungauged basins: first, it is based on mathematical representation of processes judged as important a priori by the modeller, and not inferred from available catchment response data. Second, because of their distributed nature such models demand the specification of a large number of parameters, many of which are not normally available. Thirdly, while catchment response is characterised in terms of small scale process theories, there is no mechanism to explicitly represent processes and their interactions that control hydrological response at the catchment scale over long time scales.

On the other hand, the alternative downward approach (Sivapalan et al., 2003b; Sivapalan and Young, 2005) is a data-based method that is focused on models that directly link rainfall to runoff at the time and space scales of interest, and therefore has the advantage that it is less focused on processes and unknown process parameterizations at small scales. It starts with the simplest possible model and model complexity is then increased through systematic and stepby-step incorporation of appropriate process descriptions at progressively smaller scales, identifying the possible causes of observed variability in the hydrological regime (Klemes, 1983; Wittenberg and Sivapalan, 1999; Jothityangkoon et al., 2001; Atkinson et al., 2002; Farmer et al., 2003; Sivapalan and Young, 2005). The aim here is to identify the model components and therefore the related hydrological processes that are significant in terms of simulation reliability at the catchment scale. In this kind of approach usually the models are of the conceptual type (Manabe, 1969; Chiew et al., 1993; Milly, 1994a, b), and are often found to be sufficient to explain the causes of observed patterns of streamflow response at the catchment scale and at longer time scales. They can be lumped or semi-distributed and usually contain a relatively small number of parameters that sometimes have a conceptual meaning, but nevertheless cannot be measured in the field. Being capable of capturing broad scale features (in space and time), lumped models can be useful for regionalization efforts. Moreover, due to their relatively simple structure and limited number of parameters they are less prone to equifinality problems and therefore may allow one to minimise the uncertainty in the investigation of the main hydro- logical processes occurring in the catchment. Thus, even though the simple structure of lumped models does not allow one to reproduce the dynamics of the runoff formation at the local scale, this class of approaches turns out to be useful in order to obtain a first indication about the dynamics of runoff formation processes at the catchment scale. Since the main goal of this paper is to identify the dominant hydrological structure in the study catchment the application of the downward approach is expected to provide useful insights.

Accordingly, the present article proposes the application of the downward approach (i.e. conceptual models) to gain insights into the dominant runoff generation processes within the Seventeen Mile Creek, a tropical catchment located in Northern Territory, Australia. The available hydrological information is first analyzed to obtain a preliminary indication about possible process interactions that may underlie the observed streamflow response. Subsequently, an application of the downward approach is adopted to derive the structure of a multiple bucket model that is capable of capturing the dominant processes at the catchment scale over long time scales (e.g., multiple years). The same model is then applied to carry out a sensitivity analysis, with regard to soil depths and rainfall timing. This will provide a proof of the model efficiency and some more insights about the hydrological behaviours of tropical catchments.

The insights obtained from this study will allow hydrologists to gain broad understanding of the hydrology of this region and into the dominant processes responsible for runoff generation in tropical catchments in general. Moreover, the possibility of identifying key hydrological features, combined with similar studies from other catchments around the world, may contribute in future to our efforts at a rational classification of catchments for regional hydrological studies and predictions, which is an acknowledged aim of the PUB initiative (McDonnell and Woods, 2004).

\section{The study catchment}

Seventeen Mile Creek is a tributary of Katherine River, in the Northern Territory of Australia (see Fig. 1a). The study catchment is part of the Nitmiluk National Park and has an area of $619 \mathrm{~km}^{2}$ at Waterfall View, where a discharge gauging station is located as shown in Fig. 1b. The climate of the region is monsoonal, with $90 \%$ of the rainfall falling between October and April. Two distinct seasons are identifiable: the wet season from October to the middle of April (200 days) and the dry season from the middle of April to the end of September.

The most relevant geological formations covering the watershed are Cretaceous sandstones that are characterised by a high water retention capacity. As reported by Christian and Stewart (1953) and Mulder and Whitehead (1988) the landscape of the Seventeen Mile Creek is variegated, characterised by steep dissected slopes, rounded hills and flat 
tablelands. Springs are present and originate in areas of swampy ground in the tablelands, but no other open water is present (Begg et al., 2001).

The soils are well drained with a surface texture commonly of sandy loam changing to sandy clays and clay subsoils deeper than $1-1.5 \mathrm{~m}$ with a massive and earthy structure (Hutley et al., 2000, 2001). The vegetation consists of open forests and wetlands. There is no abundance of mid-stratum tree species, while understorey vegetation is dominated by sorghum, and shrubs are sparse.

The Department of Infrastructure, Planning and Environment (DIPE) of the Northern Territory monitors the catchment using two raingauges and a stream gauging station (Fig. 1b). The first rain gauge is placed at Below Falls (DIPE code R8140160), and has been in operation from 30 October 1974. The second raingauge is located at Upper Catchment (DIPE code R8140159), and was in operation from 7 January 1973 to 7 December 1995.

A river flow gauging station is located at Waterfall View (see Fig. 1b) and gauged river flows from 1 October 1975 to 30 September 1994 are used in this study. Since for the rainfall-runoff analysis we need concurrent datasets of both rainfall and river flow, much of the subsequent analysis presented in this paper will be based on the period common to both the rainfall and the river flow time series. It should be noted, however, that the rainfall time series are affected by missing and poor quality data, as described by the DIPE. In fact, for each rainfall value a quality index is attributed, namely, "good continuous data", "interpolated", "estimated", "not yet available" or "not recorded". In order to improve the quality of the meteorological input, rainfall over the basin is estimated according to the following criteria: a) when equal quality data are available in the two raingauges at time $t$, mean areal rainfall over the entire watershed at the same time $t$ is computed by applying a weighted average of the two available observations; the weights are computed using the Thiessen polygon method; $b$ ) when different quality data are available at time $t$, the rainfall observation characterised by the higher quality is adopted as the estimate of the mean areal rainfall over the basin. The resulting annual rainfall totals estimated over the basin over the entire study period show considerable inter-annual variability, with a mean of $1075 \mathrm{~mm}$ and a standard deviation of $267 \mathrm{~mm}$, as shown in Fig. 2.

An exception to the above procedure was used for the year 1975. In that year, although the total annual rainfall is only slightly different in the two rain gauges, according to the quality criterion described above, the annual precipitation showed up as a high $1800 \mathrm{~mm}$, which is much higher than what is observed in either of the two rain gauges. For this reason, over some periods of the year 1975 only, the mean areal rainfall over the basin is estimated by applying the Thiessen weighted average of the two gauges, independently of the quality of the recorded rainfall data in both. In this way, the annual areal average rainfall in 1975 reduced to $1590 \mathrm{~mm}$.
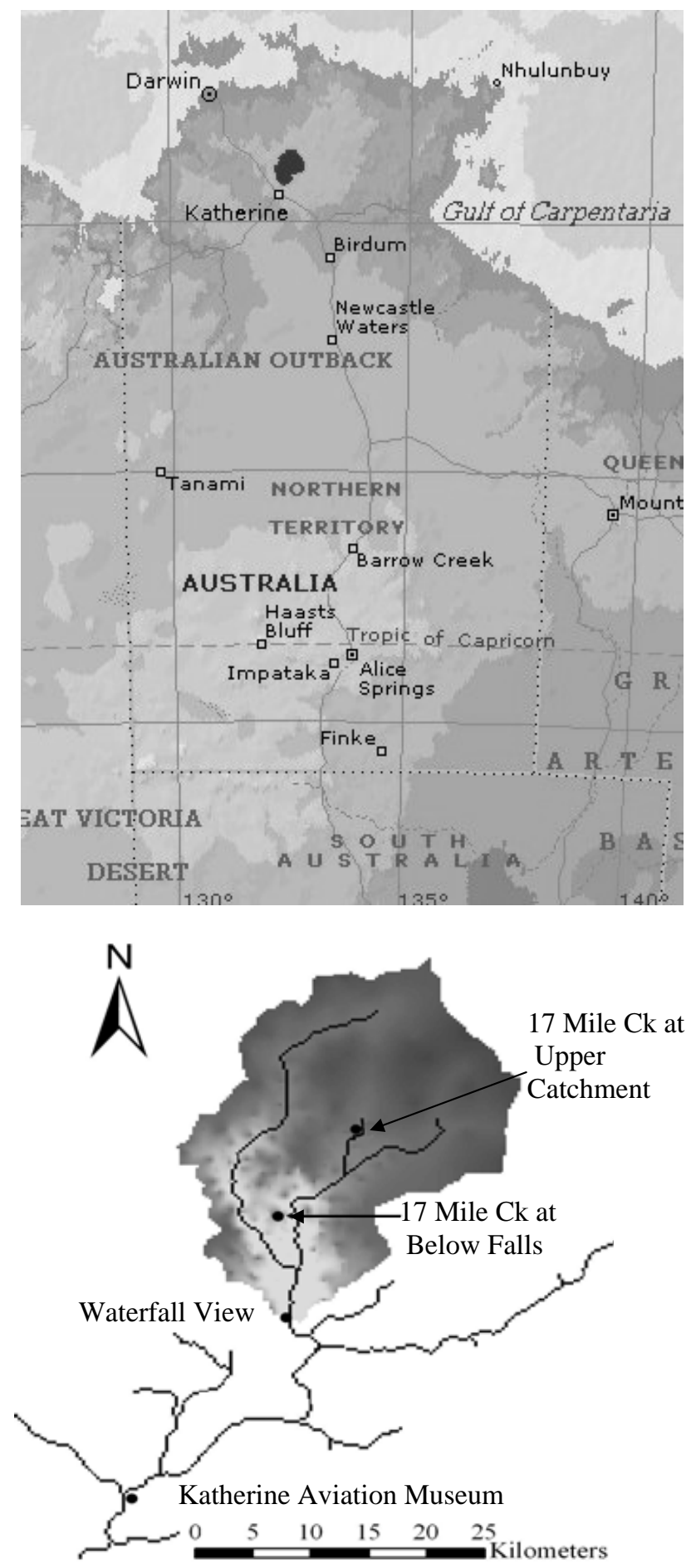

Fig. 1. (a) Location of study area in northern Australia. (b) Seventeen Mile Creek catchment and the locations of gauging stations.

Nevertheless it should be noted that the high precipitation in year 1975 was not an artefact of the procedure we adopted above to estimate rainfall over the basin. Year 1975 was indeed quite exceptional from a meteorological point of view. 

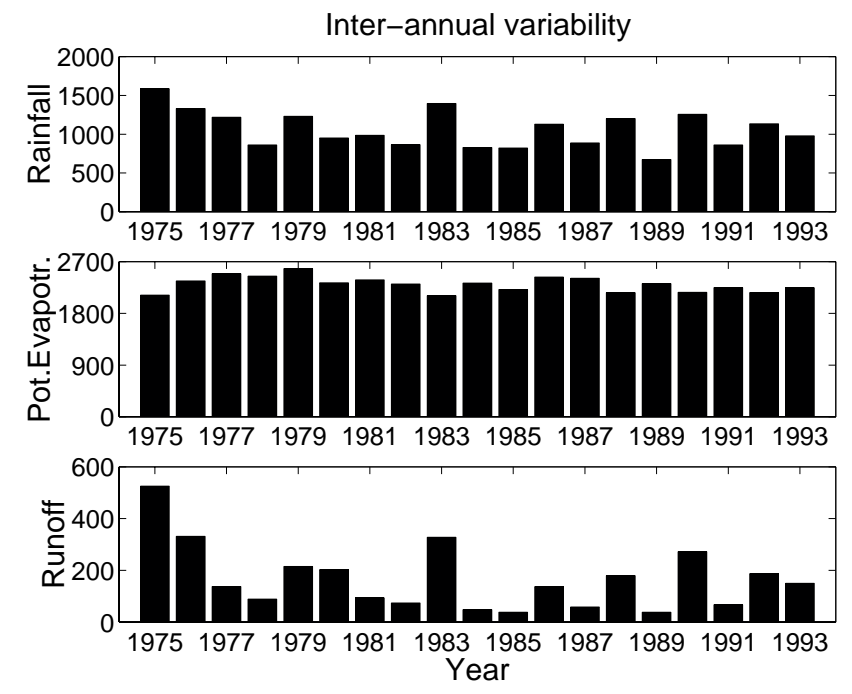

Fig. 2. Inter-annual variability of observed precipitation, observed runoff and annual potential evapotranspiration, all expressed in $\mathrm{mm}$.

The analysis of annual runoff time series (see Fig. 2) confirms this.

Daily potential evapotranspiration data were provided by the Bureau of Meteorology of Australia from three stations located within a $200 \mathrm{~km}$ radius from the centre of the catchment, namely, Mango Farm, Wooliana and Douglas. Daily potential evapotranspiration data are also available at Katherine Aviation Museum, a few kilometres from the Seventeen Mile Creek watershed (see Fig. 1b), but over a much shorter period. The statistical behaviours of the four data series are summarized in Table 1, where duration, mean and standard deviation of each record are reported. For the purposes of modelling, a composite time series over the entire time span considered in the study is constructed by combining the longer data series from Mango Farm, Wooliana and Douglas, with the shorter data series from the nearby Katherine Aviation Museum. This is done by matching the average values and standard deviations of the longer data series (from the three stations) with the corresponding values of the shorter series (i.e., at Katharine). This procedure is more effective for Wooliana station series, as it has the most different means and standard deviations compared to Katherine Aviation Museum station (see Table 1). The resulting composite time series of daily potential evaporation data (obtained as a mean of the three station rescaled observations) are then downscaled to the hourly time scale by assuming that the hourly potential evapotranspiration is constant within each day.

\section{Preliminary analysis of the rainfall and runoff regime}

An analysis of the main characteristics of the rainfall and river flow time series is first carried out. This analysis is performed in order to obtain initial indications about the domi-
Table 1. Characteristics of the observed potential evapotranspiration series (observation period, mean and standard deviation over each period) for each station.

\begin{tabular}{lccc}
\hline Station & $\begin{array}{c}\text { Period of } \\
\text { Observation } \\
\text { (year) }\end{array}$ & $\begin{array}{c}\text { Mean } \\
(\mathrm{mm} / \text { day })\end{array}$ & $\begin{array}{c}\text { Standard } \\
\text { Deviation } \\
(\mathrm{mm} / \text { day })\end{array}$ \\
\hline Douglas & $1980-1995$ & 6.22 & 1.27 \\
Mango Farm & $1980-2003$ & 6.24 & 1.27 \\
Wooliana & $1972-1980(\mathrm{Feb})$ & 6.66 & 1.97 \\
Katherine Aviation & $2000-2003$ & 6.18 & 1.24 \\
Museum & & & \\
\hline
\end{tabular}

nant runoff generation processes in the Seventeen Mile Creek catchment. These insights permit us to preliminarily identify the structure of the hydrological model to be used in order to simulate the rainfall-runoff transformation and to infer the main characteristics of the runoff regime.

\subsection{Inter-annual variability}

The computed annual potential evapotranspiration values over the catchment exhibit some inter-annual variability over the considered time span, with a mean of $2295 \mathrm{~mm}$ and standard deviation of $121 \mathrm{~mm}$. Figure 2 illustrates the interannual variability over the study period exhibited by annual potential evapotranspiration and runoff. The latter has mean value of $162 \mathrm{~mm}$, and a standard deviation of $127 \mathrm{~mm}$. The Budyko curve (Budyko, 1974; see Fig. 3) is chosen as a means to represent the annual water balance of the catchment and to identify anomalous years. The index of aridity (the ratio of annual potential evapotranspiration to annual precipitation) based on individual years varies from 1.3 to 3.5 and therefore the catchment is predominantly arid. The effective evapotranspiration, $E(t)$, over the basin can be computed by applying the continuity equation at the catchment scale, under the assumption that all the unaccounted losses of infiltrated water reach the basin outlet, namely:

$E(t)=P(t)-Q(t)$

where $P(t)$ and $Q(t)$ are the annual rainfall [mm] and annual runoff [mm], respectively. The ratio $E(t) / P(t)$ varies between 0.67 and 0.95 , revealing that the runoff coefficient is low, as expected in catchments in monsoonal climate regions. The lower and upper values of rainfall, runoff and potential evapotranspiration are reached in 1989 and 1975, respectively (see Fig. 2), when the index of aridity assumes the highest and lowest values, in that order.

\subsection{Intra-annual variability}

Mean monthly potential evapotranspiration and mean monthly rainfall are out of phase within the year, as seen 


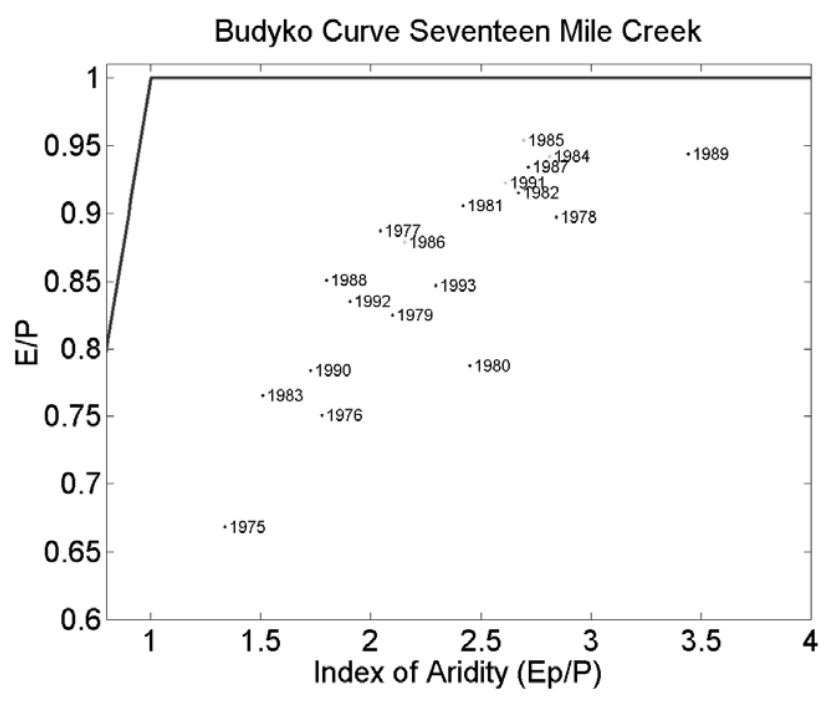

Fig. 3. Budyko Curve. Water limited environments are characterised by points lying below the continuous line.

in Fig. 4, where these variables are presented starting from October, the month with the lowest runoff value which is numbered as month 1 (i.e., start of the water year). The maximum of mean monthly runoff is reached between January and February (namely months 4 and 5 in the water year, as shown in Fig. 4), during which the potential evapotranspiration and the rainfall reach their minimum and maximum values respectively, causing maximization of the soil moisture storage and the runoff coefficient.

Figures 5a, b, c show, for a representative year (in this case 1986), taken as an example for the intra-annual trend of the hydrological variables, the progress of cumulative monthly rainfall, cumulative monthly runoff (over the water year), and also the cumulative monthly runoff plotted against cumulative monthly rainfall (the slope of the latter curve is the monthly runoff coefficient). Although rainfall starts at the beginning of the wet season, the river flow commences only 2 or 3 months later (slightly different delays are experienced in different years). This behaviour reveals the existence of an initial water deficit.

Although there is almost no rainfall during the dry season in most years, low and constant flows are still observed during this period. This delayed hydrological response is probably due to the effects of water storage within the underlying Cretaceous aquifer (see Sect. 2).

As a conclusion to this preliminary data analysis, we deduce that any hydrological model for the Seventeen Mile Creek catchment should be able to account for delayed runoff, considering that the water storage within the catchment is significant. Moreover, the runoff generation appears to be of the saturation excess type.

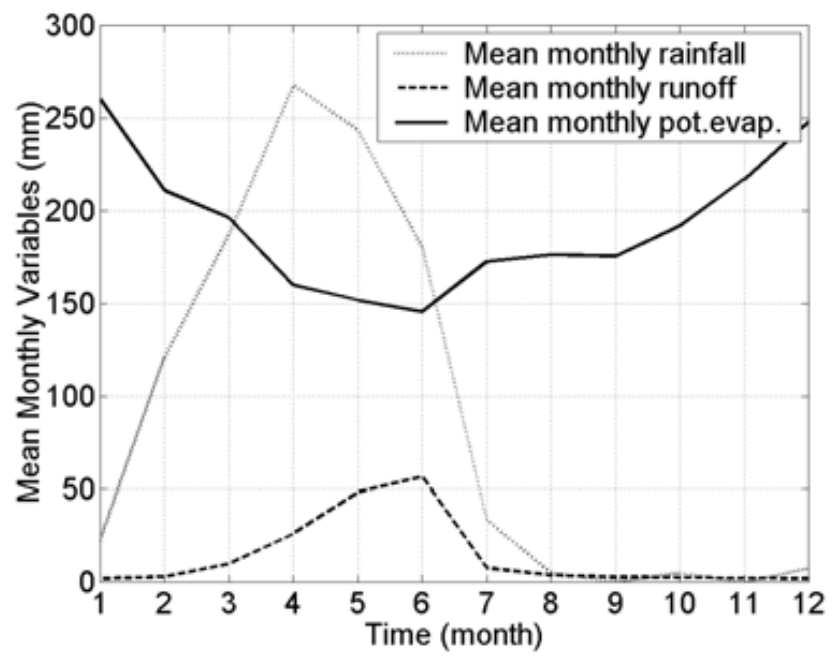

Fig. 4. Mean monthly values of rainfall (averaged over the whole considered period, i.e. from 1975 to 1994), potential evapotranspiration and runoff (in $\mathrm{mm}$ ), (October is month 1 ).
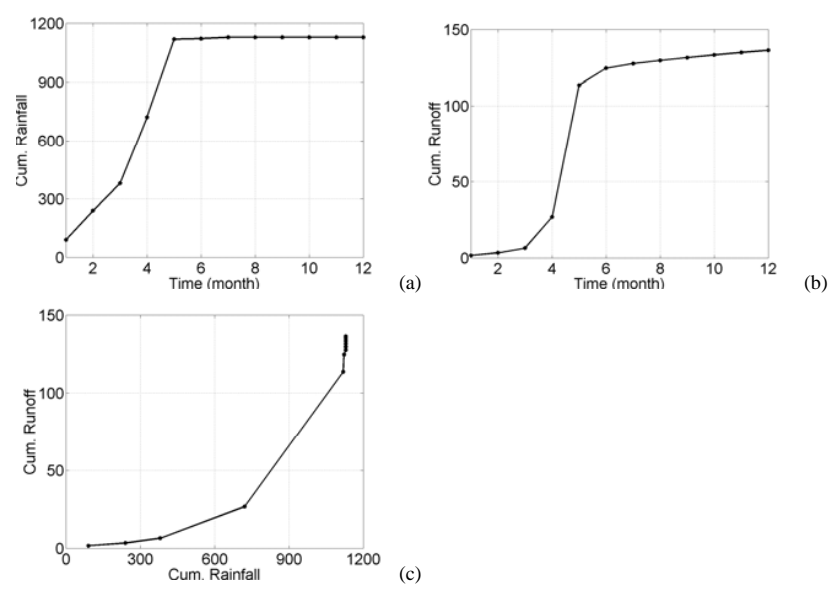

Fig. 5. Cumulative plots of (a): monthly rainfall (mm/month) and (b): monthly runoff ( $\mathrm{mm} / \mathrm{month})$ over the water year (October is month 1) for the year 1986, and (c) cumulative monthly runoff $(\mathrm{mm} / \mathrm{month})$ plotted against cumulative monthly rainfall (mm/month) for the same year.

\section{A hydrological model for Seventeen Mile Creek}

The bucket model (Manabe, 1969; Milly, 1994a, b) is a simple conceptual model, characterized by a small number of parameters. It permits one to reproduce different runoff generation mechanisms within a simple framework, where many of the parameters have a physical meaning. The scientific literature has repeatedly demonstrated the value of simple models for assessing and capturing the main or dominant hydrological behaviour of catchments (Milly and Dunne, 1994). Within the realm of the conceptual approach, models of a wide range of complexities can be constructed, ranging from 


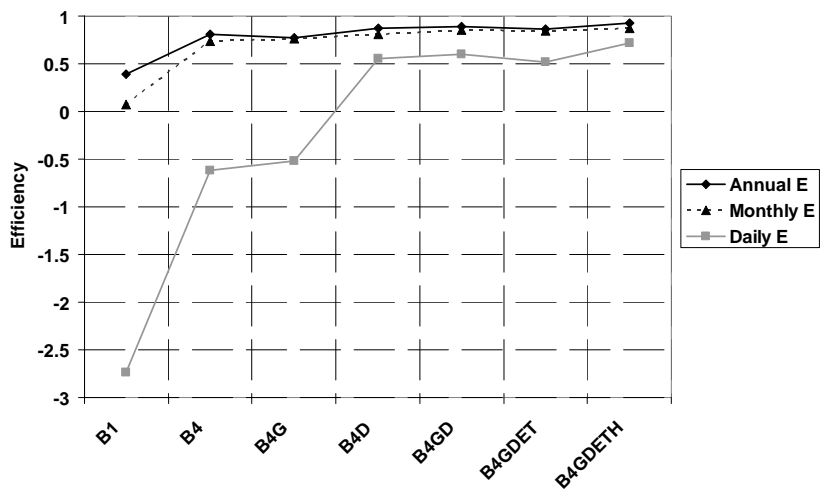

Fig. 6. Nash and Sutcliffe Efficiency for different model structures $(\mathrm{B} 1=$ a single bucket, $\mathrm{B} 4=4$ buckets in parallel, $\mathrm{B} 4 \mathrm{G}=$ 4 buckets in parallel with groundwater flow, B4D $=4$ buckets in parallel, with delayed runoff, B4GD $=4$ buckets in parallel, with groundwater flow and delayed runoff, B4GDET $=4$ buckets in parallel, with groundwater flow, delayed runoff and evapotranspiration, B4GDETH $=4$ buckets in parallel, with groundwater flow, delayed runoff and evapotranspiration, at hourly implementation).

a single bucket model to multiple bucket models of differing sizes organised in series or in parallel. In this paper, we are interested in developing a model of sufficient complexity that we can then use to explore the characteristic runoff behaviour in the study catchments. In order to develop this model we use the downward approach (Jothityangkoon et al., 2001; Farmer et al., 2003; Atkinson et al., 2002): we start with the simplest possible model (i.e. single bucket model), and increase the model complexity step by step by testing the model results against signatures of observed runoff variability at the annual, monthly and daily time scales. Model performance at every step is ascertained using the Nash and Sutcliffe (1970) efficiency, by running the simulation over the whole observation period without applying a split sample procedure that would allow a model validation. In fact, calibrating the model on a reduced amount of data would increase the uncertainty in the evaluation of the dominant hydrological processes. As the scope of our analysis is not to set up a prediction model per se but instead to use a modelling approach to understand the dominant runoff generation processes in this catchment, we decided that it was preferable to focus instead on reduction of calibration uncertainty. In this study we adopted a manual calibration procedure because we believed that in the presence of uncertainty a mixed quantitative and perceptual evaluation of the different modelling solutions would be a suitable choice. In fact, automatic calibration discriminates the different models and parameter sets on the basis of a specified objective function that may yet fail to comprehensively evaluate the goodness of fit.

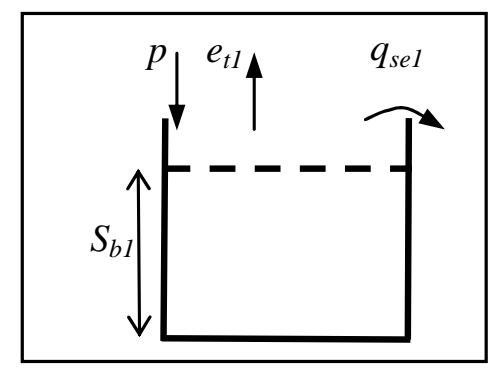

Fig. 7. Sketch of the B1 model. Only saturation excess runoff is included.

\subsection{Model development}

A first modelling attempt is made with a single bucket model (B1, see Fig. 7). The runoff is assumed to be caused by saturation excess overland flow, $q_{s e}(t)[\mathrm{mm} / \mathrm{s}]$, when the maximum soil water capacity of the bucket, $S_{b}[\mathrm{~mm}]$, is exceeded. The model is based on the continuity equation that, in the finite difference form, can be written as

$\frac{\Delta s(t)}{\Delta t}=p(t)-q_{s e}(t)-e(t)$

where $s(t)[\mathrm{mm}]$ is the water storage in the bucket at time $t$ and $e(t)[\mathrm{mm} / \mathrm{day}]$ is the effective evapotranspiration. Equation (2) is solved at daily time step by applying the first order Runge-Kutta method (Euler method). The saturation excess runoff, $q_{s e}(t)[\mathrm{mm} / \mathrm{day}]$, is computed by

$q_{s e}(t)=\left(s(t)-S_{b}\right) / \Delta t$ if $s(t)>S_{b}$,

$q_{s e}(t)=0$ if $s(t) \leq S_{b}$.

$e(t)[\mathrm{mm} /$ day $]$ is estimated based on the potential evapotranspiration $e_{p}(t)$ [mm/day],

$e(t)=\frac{s(t)}{S_{b}} e_{p}(t)$.

A first guess value for $S_{b}$ was obtained by multiplying the mean soil depth, $D[\mathrm{~mm}]$, by the mean soil porosity, $\phi[-]$. These two parameters were estimated on the basis of the available qualitative information about the soil types existing over the catchment. In a subsequent phase, the parameters are estimated through manual calibration to better simulate the observed runoff at annual, monthly and daily time scales. Values of $1250 \mathrm{~mm}$ and 0.45 are arrived at in this way for the mean soil depth and porosity, respectively.

However, model B1 gives unreliable simulations (see Fig. 6). During dry years the model generates no runoff at all, whereas during the wet years the annual runoff is overestimated. Therefore, models with an increasing number of buckets (of different sizes) acting in parallel are subsequently 


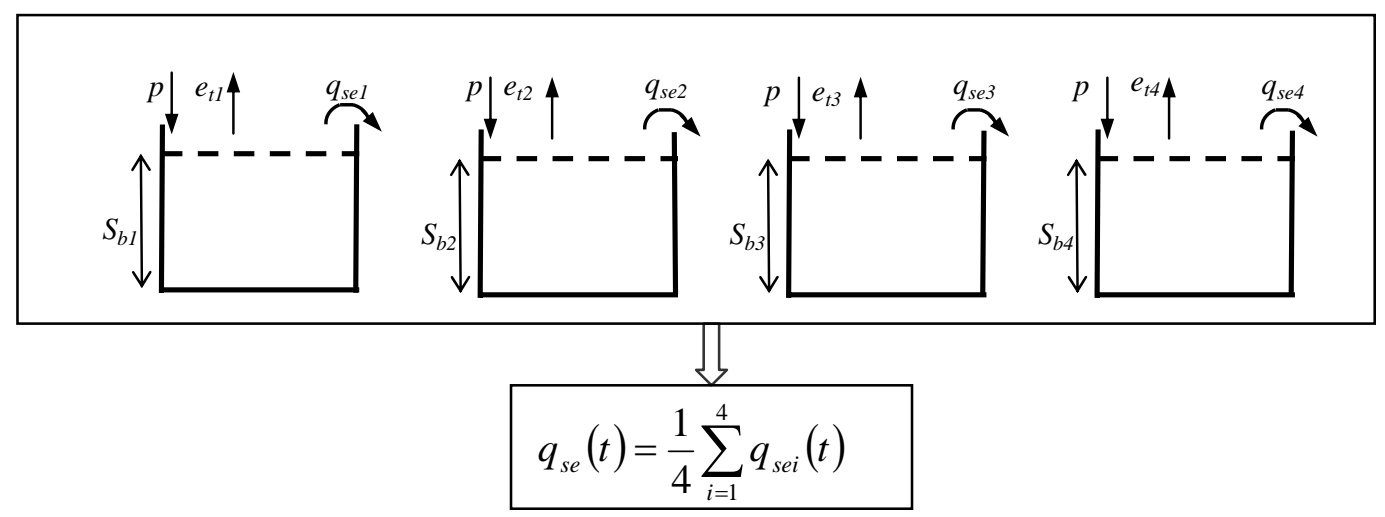

Fig. 8. Sketch of model B4. Only saturation excess runoff is included.

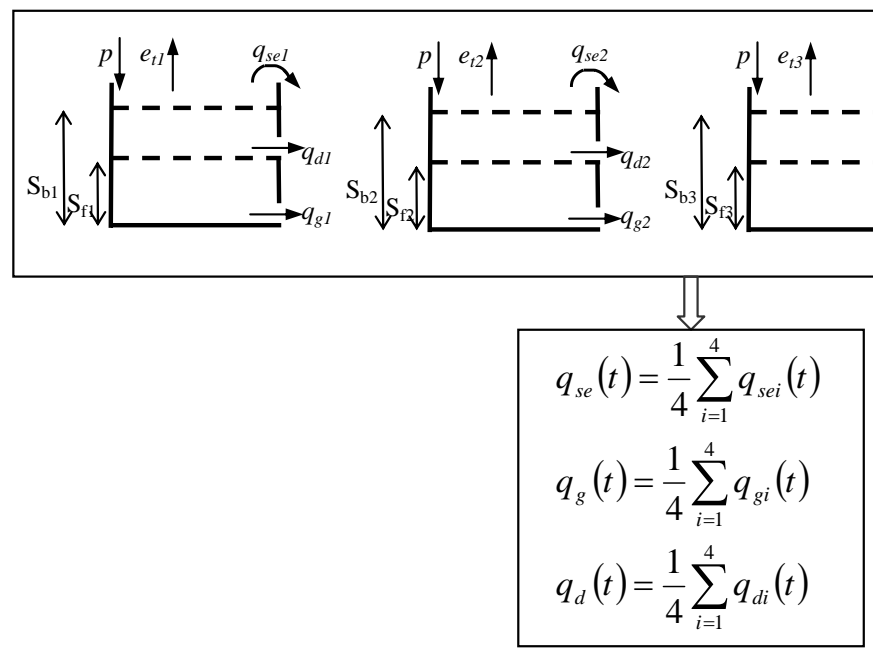

Fig. 9. Model B4DG, composed of four buckets in parallel. Saturation excess runoff, delayed runoff and groundwater flow are accounted for.

considered (Fig. 8), taking into consideration only the saturation excess runoff. The optimal number of buckets is identified by maximizing the fit to the observed runoff at the annual and monthly time scales. The discharge is assumed to be the mean of the discharges from the buckets. A four bucket model is finally selected after manual calibration and its estimated parameter values are presented in Table 2 . The runoff simulations by the model are satisfactory at the annual and monthly time scales (see efficiency in Fig. 6); however, at the daily time scale, the model tends to produce an overestimation of the peak flows. Therefore, the four bucket model is subsequently improved by introducing additional process complexity. After attempting various modeling solutions, which are not described here for the sake of brevity, a four bucket model with a groundwater flow component and a delayed runoff component (model B4GD, see Fig. 9) is set up. The difference equation for model B4GD is:
Table 2. Parameter values for model B4.

\begin{tabular}{lll}
\hline $\begin{array}{l}\text { Type of } \\
\text { soil }\end{array}$ & $\begin{array}{l}\mathrm{D} \\
(\mathrm{mm})\end{array}$ & $\begin{array}{l}\phi \\
(-)\end{array}$ \\
\hline 1 & 300 & 0.27 \\
2 & 1700 & 0.40 \\
3 & 2000 & 0.45 \\
4 & 3000 & 0.45 \\
Mean & 1750 & 0.39 \\
\hline
\end{tabular}

$\frac{\Delta s(t)}{\Delta t}=p(t)-q_{s e}(t)-q_{d}(t)-q_{g}(t)-e(t)$

where $q_{g}(t)$ [mm/day] and $q_{d}(t)$ [mm/day] are the groundwater flow and the delayed runoff, respectively. The 
Table 3. Parameter values for model B4DG.

\begin{tabular}{llllll}
\hline $\begin{array}{l}\text { Type of } \\
\text { soil }\end{array}$ & $\begin{array}{l}\mathrm{D} \\
(\mathrm{mm})\end{array}$ & $\begin{array}{l}\phi \\
(-)\end{array}$ & $\begin{array}{l}\mathrm{f}_{c} \\
(-)\end{array}$ & $\begin{array}{l}\mathrm{a} \\
(\text { day })\end{array}$ & $\begin{array}{l}\mathrm{b} \\
(-)\end{array}$ \\
\hline 1 & 900 & 0.43 & 0.15 & 150 & 0.2 \\
2 & 1800 & 0.43 & 0.28 & 150 & 0.2 \\
3 & 2500 & 0.45 & 0.28 & 150 & 0.2 \\
4 & 3500 & 0.50 & 0.37 & 150 & 0.2 \\
Mean & 2175 & 0.45 & 0.27 & 150 & 0.2 \\
\hline
\end{tabular}

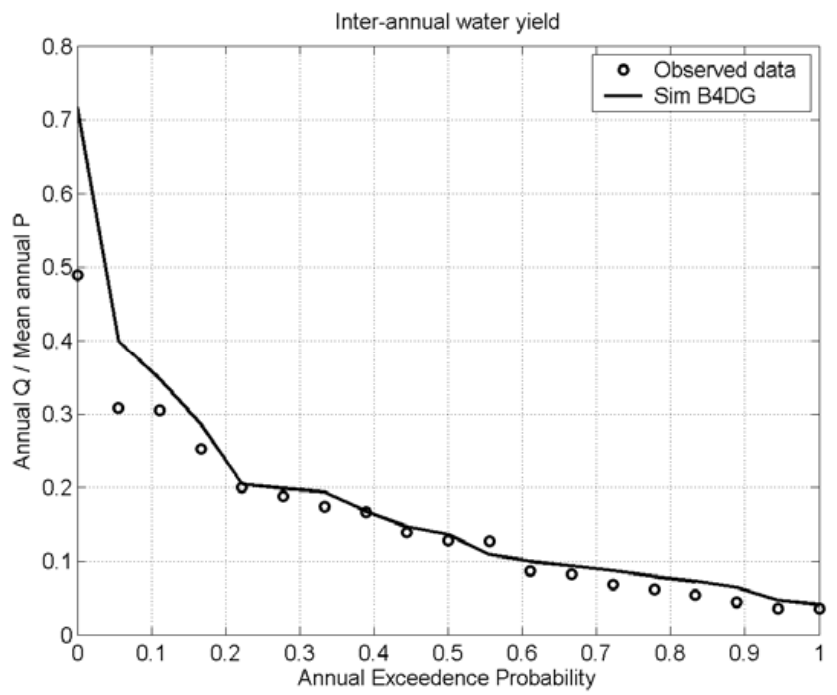

Fig. 10. Inter-annual variability: comparison of annual model simulations by the model B4DG against observed values presented in the frequency domain, with $Q$ and $P$ indicating the runoff and the precipitation, respectively.

groundwater flow is computed with the linear relationship

$q_{g}(t)=\frac{s(t)}{t_{g}}$.

Here $t_{g}$ is a parameter that may be comparable with the mean residence time of the catchment, as far as the groundwater flow is concerned. The delayed runoff $q_{d}(t)$ is obtained as

$q_{d}(t)=\left(\frac{s(t)-s_{f}}{a}\right)^{\frac{1}{b}}$ if $s(t)>s_{f}$,

$q_{d}(t)=0$ if $s(t) \leq s_{f}$,

where the threshold $s_{f}[\mathrm{~mm}]$ is obtained by multiplying the soil depth $D$ by the soil field capacity $f_{c}[-]$, the parameters $a$ [day] and $b[-]$ are estimated by optimising the model simulation of the recession curves of the observed hydrograph. A non-linear formulation for the delayed runoff is adopted because it provides satisfactory results in terms of superior simulations of the recession curves at the daily scale.

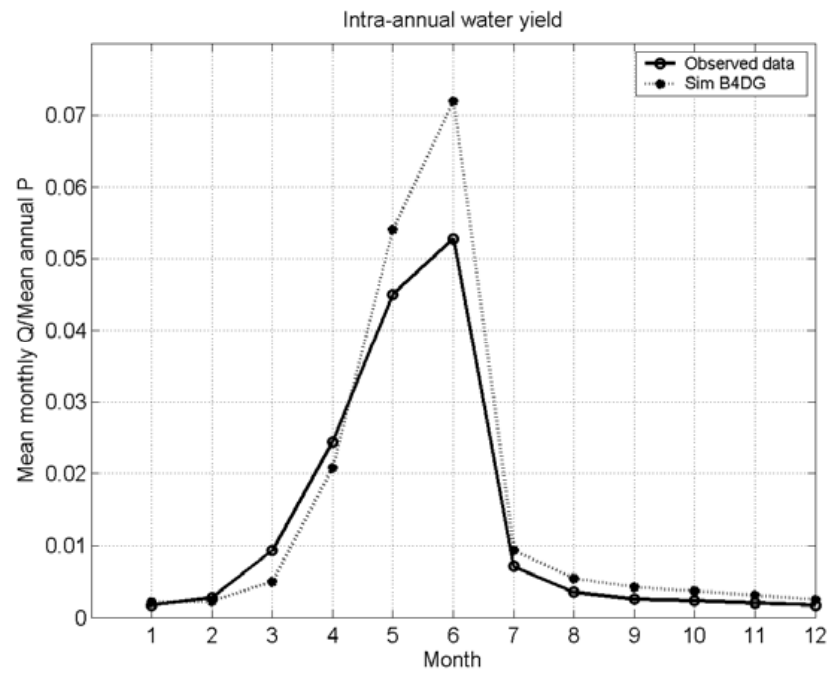

Fig. 11. Intra-annual variability: comparison of model simulations of mean monthly runoff by the model B4DG against observed values, with $Q$ and $P$ indicating the runoff and the precipitation, respectively.

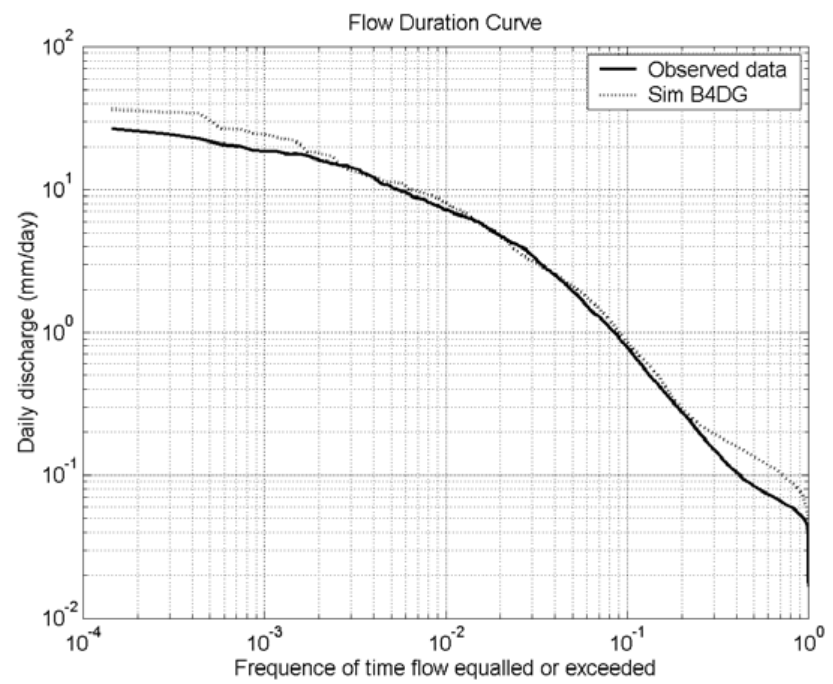

Fig. 12. Daily flow duration curve: comparison of the predicted flow duration curve by the model B4DG against observed values.

The parameters of the model B4GD are optimised through manual calibration carried out by comparing the model results against actual observations, at the chosen time scales. The final parameter values obtained through calibration are presented in Table 3. The results of the simulations at the annual, monthly and daily scales are reported in Figs. 10, 11 and 12. The mean monthly runoff in Fig. 11 is divided by the mean annual rainfall, so that the fraction of annual rainfall converted into runoff during each month and the months giving the highest contributions are easily identified. The trend is more or less the same during all of the considered years. 


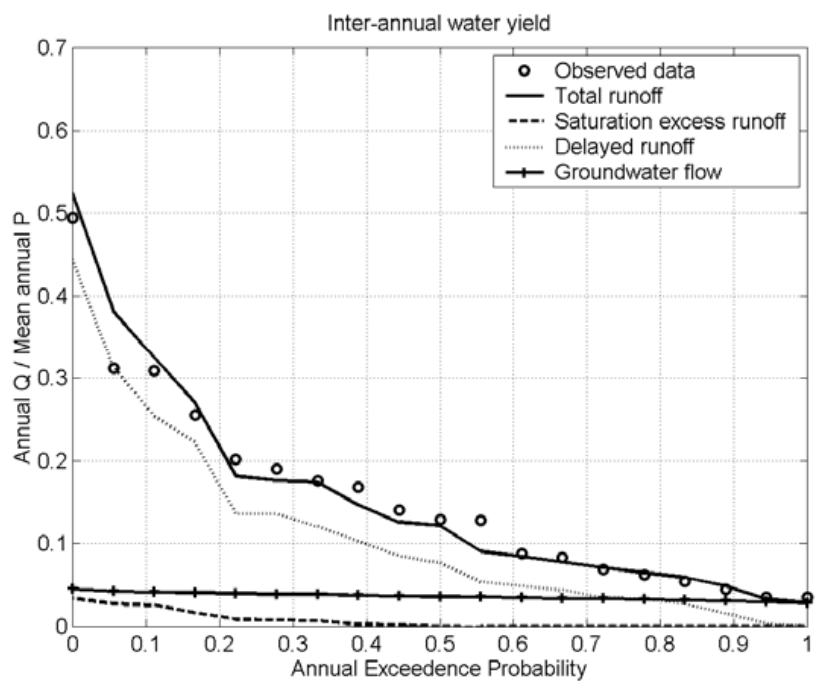

Fig. 13. Inter-annual variability: simulations of annual runoff by the model B4DGETh partitioned into different runoff components (saturation excess, delayed runoff and deep groundwater runoff), with $Q$ and $P$ indicating the runoff and the precipitation, respectively.

Overall, one can see an overestimation of the highest runoff values. By looking in detail at the different runoff components, it appears that delayed runoff plays a significant role. This is confirmed by observing that the hydrograph recession curve is recorded over several days, because of the limited slope and the local aquifers and swampy areas. The efficiency (Nash and Sutcliffe) of the obtained daily flow duration curve is now 0.97 , while the efficiency of daily runoff during the whole simulation period is 0.69 .

In order to mitigate the simulation inaccuracy of peak flows, the model is run at the hourly time step and a more detailed modelling scheme is introduced. This formulation represents the evapotranspiration by decomposing it into bare soil evaporation $e_{b}(t)[\mathrm{mm} / \mathrm{h}]$ and plant transpiration (model B4DGET, having daily time step and model B4DGETh, with hourly time step). In particular, evapotranspiration is computed using the following expressions:

$e_{b}(t)=\frac{s(t) \cdot(1-M) \cdot e_{p}(t)}{S_{b}}$,

$e_{v}(t)=M k_{v} e_{p}(t)$ if $s(t)>s_{f}$

$e_{v}(t)=\frac{s(t) M k_{v} e_{p}(t)}{s_{f}}$ if $s(t) \leq s_{f}$.

where $e_{p}(t)[\mathrm{mm} / \mathrm{h}]$ is the potential evapotranspiration at time $t$ and $M[-]$ is the fraction of forest vegetation cover, comprised of values between 0 and $1 ; e_{v}(t)[\mathrm{mm} / \mathrm{h}]$ is the vegetation transpiration that is computed with two different formulations, depending on the amount of water, $s(t)$, that is stored in each bucket; and $k_{v}[-]$ is the plant transpiration efficiency, which is usually set to 1 (Eagleson, 1978).

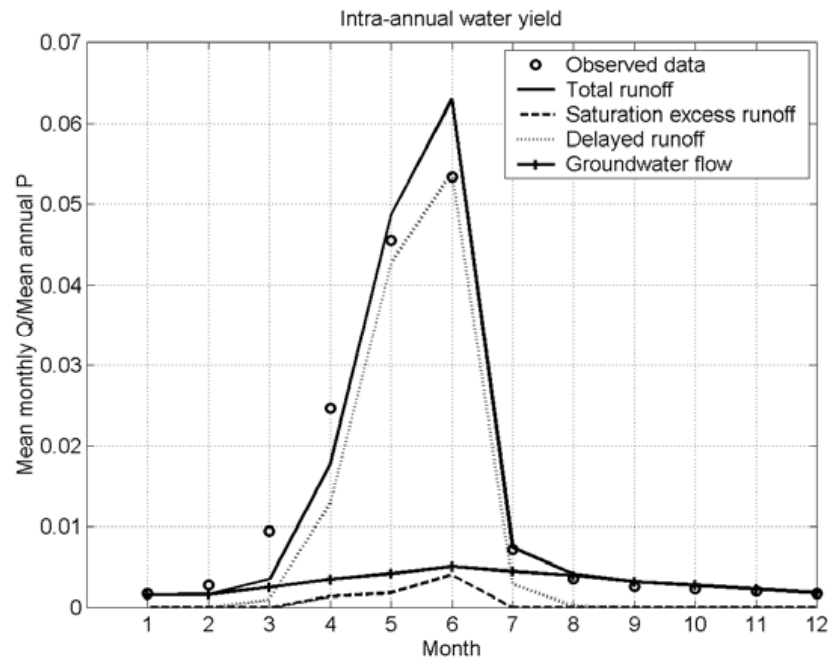

Fig. 14. Intra-annual variability: simulations of the model B4DGETh at the monthly time scale partitioned into different runoff components, with $Q$ and $P$ indicating the runoff and the precipitation, respectively.

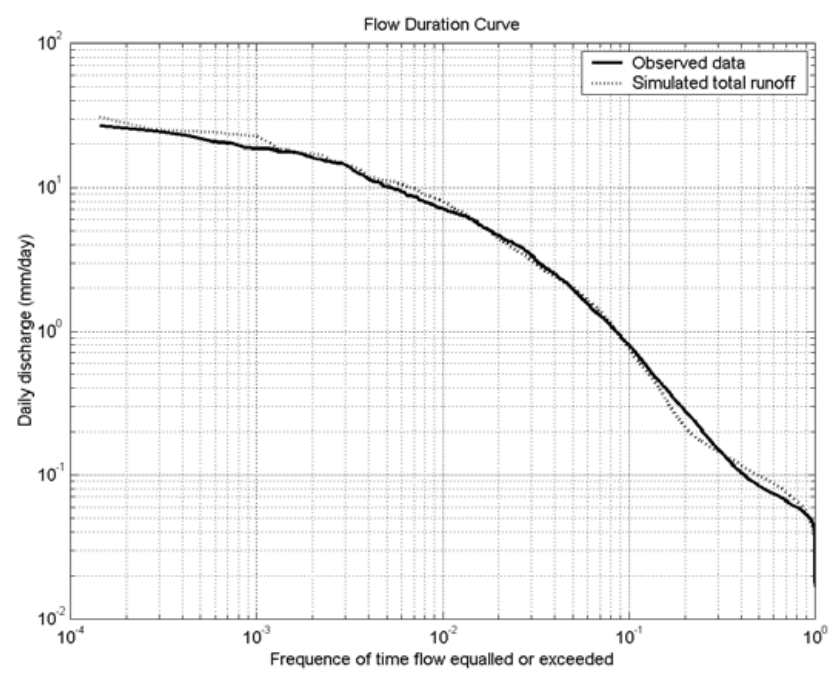

Fig. 15. Flow duration curve: comparison of the daily flow duration curve predicted by the model B4DGETh against observations.

The value of $M$ is found through manual calibration, starting from a value obtained from the analysis of the vegetation cover data, leading to the chosen value of 0.2. According to the premise stated above, the model equation needs to be solved at hourly time step. This is given by:

$$
\frac{\Delta s(t)}{\Delta t}=p(t)-q_{s e}(t)-q_{d}(t)-q_{g}(t)-e_{b}(t)-e_{v}(t) \text {. }
$$

Since only a single realization of the rainfall series is available, and due to the lack of information on the hydraulic geometry and surface roughness characteristics, no routing is implemented in the model. Indeed, uncertainty in the 
Table 4. Performance indices of model B4DGETh.

\begin{tabular}{lllll}
\hline $\begin{array}{l}\text { Performance } \\
\text { index }\end{array}$ & $\begin{array}{l}\text { Worst an- } \\
\text { nual value } \\
\text { over the } \\
\text { entire series }\end{array}$ & $\begin{array}{l}\text { Best annual over } \\
\text { the entire } \\
\text { series }\end{array}$ & $\begin{array}{l}\text { Value over } \\
\text { the entire }\end{array}$ & $\begin{array}{l}\text { Value of } \\
\text { the flow } \\
\text { duration } \\
\text { curve }\end{array}$ \\
\hline Efficiency & 0.08 & 0.91 & 0.72 & 0.99 \\
\hline
\end{tabular}

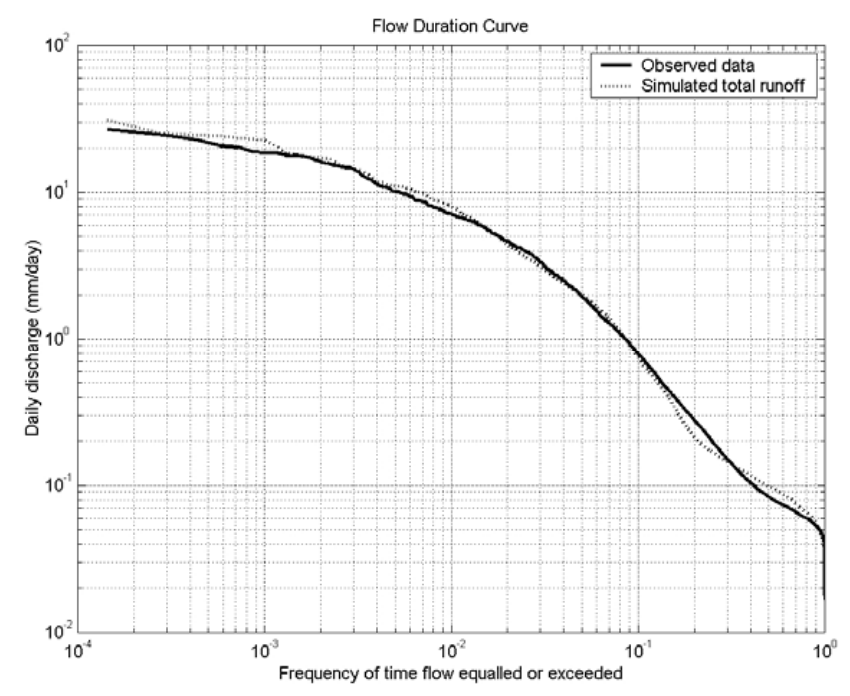

Fig. 16. Cumulative daily runoff versus cumulative daily rainfall for every year of record: results presented only in the rainfall range of $600 \mathrm{~mm}$ to $1200 \mathrm{~mm}$ for clarity (year 1975 has been excluded as considered anomalous).

observed data precludes any fine time scale representation. The hourly results are therefore aggregated to the daily time scale. The simulations of this model at different time scales are presented in Figs. 13, 14 and 15, from where it can be inferred the importance of the delayed runoff in the study catchment, while saturation excess runoff occurs only during and immediately after heavy rainfall events. In fact, although the soils in this area are relatively thin, the presence of a local deep groundwater aquifer and extensive swamps, and the limited slope of the topography, induce significant water storage within the basin, and contribute to significant volumes of delayed runoff. Figure 14 shows that the saturation excess runoff mechanism is not as relevant as the delayed component. However, it is necessary to take it into account because it substantially contributes to the formation of the daily runoff peaks. If the saturation excess runoff was not considered, the daily peaks would be underestimated and the recession curve of the hydrograph would become less steep than the observed one, as water from the catchment would be released over a longer period of time.
The Nash and Sutcliffe (1970) efficiency of the model B4DGETh at the daily timescale and over the whole observation period is 0.72 , as shown in Table 4 , where the goodness of fit indices for this model are reported. This is a satisfactory result in comparison to analogous outcomes obtained for similar applications presented in the scientific literature.

A more detailed analysis of the accuracy of the results can be carried out by looking at the goodness of the fit in some individual years. By ranking the model efficiencies in each year in ascending order, and excluding the worst and the best years (in order to ignore the two extremes), one can see that during the remaining period the worst efficiency $(0.20)$ was achieved in 1985 while the best (0.81) was obtained in 1976. The reason for such different model behaviours in different years is probably the different orders of magnitude of the total annual runoff volume. In fact, the maximum runoff in 1985 is less than $1.5 \mathrm{~mm}$, while in 1976 it reaches the value of $22 \mathrm{~mm}$. One can argue that the model is probably less accurate in the simulation of the low flows. In the latter case, the errors in the estimation of the mean areal rainfall are the probable cause of poor results. The Nash efficiency obtained for years having less than $150 \mathrm{~mm}$ of runoff, estimated by averaging the efficiencies on daily results for those years, is 0.54 . For the remaining years recording higher annual runoff the average efficiency is 0.70 . These results indicate that the poor reliability of the available hydrological data might compromise the results, with significant impacts on low flow simulations. However, it is important to note that, by using a simple bucket model, a satisfactory mean efficiency has been reached without requiring more sophisticated automatic calibration routines. This might help in identifying the most important runoff generation mechanisms in this catchment, while more complex models might exacerbate the problem of equifinality (Beven, 2002), leading to erroneous conclusions even if the model performances may appear to be satisfactory.

\subsection{Investigation of anomalous years}

Figure 16 shows the plot of cumulative runoff against cumulative rainfall separately for each year of the observation period. One can see considerable variability between years. In order to better investigate the physical reasons of such variability, we will focus on the years 1977 and 1990. Even 
Table 5. Comparison of annual runoff values (mm/year), obtained from the same annual precipitation that fell at a constant rate over 100 days, in different periods of the wet season, for 5 selected years of the observation period.

\begin{tabular}{llll}
\hline $\begin{array}{l}\text { Period of } \\
\text { rainfall/ } \\
\text { year }\end{array}$ & $\begin{array}{l}\text { Beginning } \\
\text { of wet } \\
\text { season }\end{array}$ & $\begin{array}{l}\text { Middle of } \\
\text { wet season }\end{array}$ & $\begin{array}{l}\text { End of wet } \\
\text { season }\end{array}$ \\
\hline 1976 & 239 & 353 & 387 \\
1979 & 150 & 231 & 259 \\
1983 & 321 & 402 & 418 \\
1987 & 70 & 82 & 87 \\
1991 & 64 & 82 & 92 \\
\hline
\end{tabular}

though the total (i.e. cumulative) annual rainfall is almost the same for the two years (a high value of $\sim 1200 \mathrm{~mm}$ ), total runoff is considerably different: $140 \mathrm{~mm}$ in 1977 and $280 \mathrm{~mm}$ in 1990. A similar difference in behaviour is observed in the years 1978 and 1984: almost the same (but much smaller) cumulative annual rainfall gives rise to vastly different runoff totals.

Further analysis with the multiple bucket model, including an examination of rainfall in the preceding year and season, allowed us to conclude that the explanation for such vastly different hydrological response must be sought in the characteristics of the rainfall timing occurring within each year. In fact, examination of the daily rainfall variability within the years 1977 and 1990 shows that the rainfall in 1977 occurs in the first part of the wet season, when the potential evapotranspiration is high. Moreover, the rainfall in 1977 is considerably dispersed in time. This means that both the soil's storage capacity and the storage deficit that exists in the soil at the onset of the wet season can hardly be exceeded, and it is therefore not surprising that less runoff is generated. On the other hand, in 1990 the wet season consists of a few major rainfall events that occur over a shorter time span, and therefore there is more opportunity for the above mentioned thresholds to be exceeded. The same explanation holds for the differences between years 1978 and 1984. For example, in 1978 the amount of rainfall from the 30th day to the 170th day is $846 \mathrm{~mm}$, whereas in $1984604 \mathrm{~mm}$ was observed over the same time period. In fact, in 1978 almost the entire (98\%) annual rainfall total fell over a mere 140 days.

\subsection{Investigation of the effects of intra-annual rainfall dis- tribution}

In order to better investigate the effects of the temporal (intraannual) distribution of rainfall, a further modelling analysis is conducted by using a synthetic, idealized meteorological forcing. In particular, the bucket model B4DGETh is run for the entire observation period (multiple years) by driving it with just one rainfall event per year to represent the wet

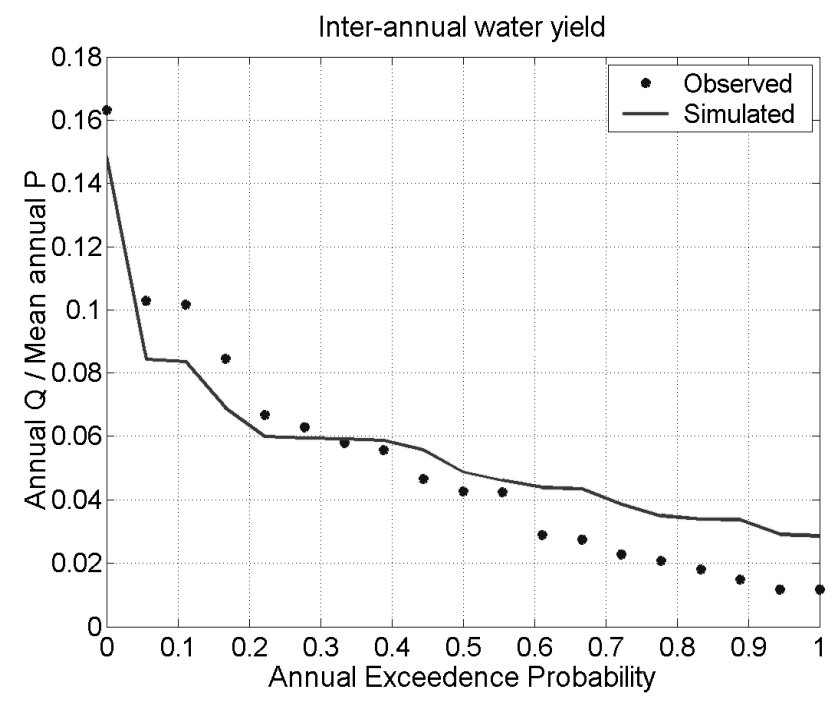

Fig. 17. Inter-annual variability: comparison of default observed values of annual runoff values (dots) and simulations by the multiple bucket model with soil depths assumed to be $200 \%$ deeper than calibrated values, with $Q$ and $P$ indicating the runoff and the precipitation, respectively.

period rainfall. Three cases are considered; in each case constant intensity rainfall input is used which is assumed to last 100 days, but with total rainfall depth equal to the recorded annual precipitation in each year. The three cases only differed in the positioning of the rainfall period (i.e. starting time) within the year: Case (1) - at the beginning of the regular wet season; Case (2) - in the middle of the wet season; and Case (3) - at the end of the wet season. The essential difference between the three cases is the positioning of the rainfall wet period in relation of the intra-annual variation of potential evapotranspiration.

The simulation results show that Case (3) is the one that produces the largest runoff volume. The reason is fairly obvious - since in this case the rainfall period almost coincides with the period over which the potential evapotranspiration is lowest. The results of this analysis are given in Table 5, where the results from five representative years are reported. We note that, even in a tropical catchment such as the Seventeen Mile Creek, the hypothesised constant rainfall is not intense enough to generate saturation excess runoff (results not reported here), which seldom occurs even when the recorded rainfall is considered. This is an important observation that needs to be considered during studies of tropical catchments.

\section{Sensitivity analysis}

The multiple bucket model is next used to carry out a sensitivity analysis of the runoff behaviour and overall water balance with respect to soil depth variations and the rainfall regime. Firstly, simulations are performed by decreasing the 
soil depths in steps of $10 \%$ of the assumed values and up to $50 \%$, while keeping the rainfall at the original value. These simulations are then repeated by increasing the soil depths up to $200 \%$ (again in steps of $10 \%$ ). Subsequently, sensitivity analysis is carried out by increasing the rainfall depths up to $50 \%$, again in steps of $10 \%$, while keeping the soil depths constant at the original values. In all cases, the model is run over the entire observation period.

The sensitivity analyses show, first of all, that the runoff volume is more sensitive to variations of rainfall depth than to variations of soil depth. On the other hand, the soil depth appears to have more impact on the partitioning of total runoff into its components, and confirms similar findings of Reggiani et al. (2000). Decreasing soil depths reduces the water storage capacity of the soil, leading to higher incidence of saturation excess runoff and a corresponding reduction of delayed runoff and groundwater runoff. Effectively, this means that the reduction of soil depth causes part of the rainfall that would have left the catchment as delayed runoff to be transformed into rapid runoff. On the other hand, the annual and monthly cumulative runoff values are not affected by these changes. On the contrary, when the soil depth is significantly increased, the larger amount of water stored in the soil induces a decrease in runoff that is discernible even at the annual time scale, in part due to the increased evapotranspiration. This observation does not apply for dry years (see Fig. 17) during which saturation excess overland flow would not occur anyway, and therefore it is not affected by the increase of soil depth, while groundwater flow is still increased, due to the effects of the increased water storage capacity of the soil.

Increase of rainfall depth contributes to a corresponding increase of runoff generation and vice versa for decreased rainfall depth. These impacts are more evident for saturation excess overland flow and delayed runoff than for groundwater flow.

\section{Conclusions}

Using the systematic "downward approach", a multiple bucket model (consisting of four buckets in parallel) was developed for a catchment in the Northern Territory, Australia. This model is considered sufficient and reasonably representative of the hydrology of this catchment and is therefore capable of depicting the dominant hydrological processes of other catchments in this region that might present similar geology and topography, high evapotranspiration and comparable rainfall regimes.

It is worth underlining that the downward approach can lead to the identification of different model structures depending on the case study. For instance, the bucket model may not be the most common suggested solution in some cases. No hypothesis about the model structure needs to be formulated a priori, the selection of the optimal approach be- ing guided by the results of the sequence of the modelling exercises.

The data base available for the considered case study does not allow us to reliably represent the hydrological processes at a sub-daily time scale. However, a hydrological simulation experiments performed at daily, monthly and annual time steps do allow us to identify the main hydrological processes leading to runoff formation. This kind of study is believed to be extremely important for the analysis of the runoff dynamics in poorly gauged basins.

Of course, the presence of uncertainty in the observed data set might cloud the results of the analysis and the conclusions. This is the reason why: (1) we used simple models, with the aim to adopt robust approaches which allow us to minimise the risk of over-parameterisation; (2) we useed the full data-base for model calibration; (3) we used the observed data for model calibration. In consideration of the simplicity of our models and the type of calibration procedure we used, we feel that the conclusions of our analysis were not overly affected by the presence of uncertainty in the observations and other data sources. In fact, the use of manual calibration has allowed us to check the results provided by the modelling solutions. We carefully inspected the reliability of each approach and the potential effects of any uncertainty. In particular, we checked that the simpler models were rejected because of their effective inability and not because of unreliable parameterisation. We are convinced that the increase in model complexity was always justified and not induced by uncertainty or lack of model fit.

In detail, the present work has allowed us to identify the delayed runoff as the most important contribution to river discharge formation over the catchment. The delayed runoff originated from water retained within the rocky aquifers underlying the catchment and perhaps also from the swamps and other characteristic landforms located around the catchment. On the other hand, saturation excess overland flow occurs rarely and only during and after high rainfall events during the wet season. Groundwater flow (i.e. baseflow) is also found to be significant and originates from the underlying Cretaceous aquifer that allows the seepage of water flow into the river over the whole dry season. During the sustained dry period, a considerable water deficit develops within the catchment until the onset of the wet season, and consequently is the cause of the delayed response of the catchment to winter rains.

The multiple bucket model is used to perform a sensitivity analysis of the overall water balance with respect to soil depth, rainfall depth and rainfall occurrence. From these analyses we can conclude, with respect to total runoff generation, that as long as the heterogeneity of the soil depth is reproduced, the catchment response is more sensitive to rainfall variations than to soil depth variations. This is an expected result for catchments having shallow soils and high rainfall precipitation, and in particular for tropical regions, in which the rainfall intensity is higher than in other climates. 
On the other hand, when looking at the partitioning of the total runoff into its components (i.e., overland flow, delayed runoff, groundwater runoff), the catchment response is more sensitive to soil depth variations.

In conclusion, important anomalies in annual runoff (i.e., inter-annual variability) are explored, with comparative analysis of years in which the annual precipitation is almost identical, whereas considerably different annual runoff totals are recorded. This analysis showed that the annual total runoff in any given year is not dependent upon dry season precipitation or runoff in the previous year, but rather depends only on the timing of the wet season within the year and its "storminess", i.e., the temporal distribution of precipitation within the wet season and within individual storms. In fact, the same total depth of rainfall produces a larger amount of total runoff if it falls over a shorter period of time (i.e., shorter wet season), thus allowing the soil's storage capacity and/or the soil-water storage at field capacity to be exceeded. Similarly, more of the annual rainfall is converted into runoff if the bulk of the rainfall occurs later in the wet season, when the potential evapotranspiration is smaller, since its intra-annual variation is out of phase with respect to the rainfall. In conclusion, important features of the catchment's runoff response and water balance behaviour have been brought out through the development and application of the multiple bucket model. This study has allowed us to gain a deeper understanding of the hydrology of tropical catchments in the Northern Territory of Australia. The indications derived for the Seventeen Mile Creek can be extended for similar catchments of the same region and may allow to better design appropriate monitoring schemes. In fact, the knowledge of the dominant runoff generation processes allows one to identify the hydrological variables that need to be monitored in order to derive fruitful indications about the state of the catchment from a hydrological point of view.

Acknowledgements. The work that is presented in this paper was carried out within the framework of the activity of the Working Group at the University of Bologna of the Prediction in Ungauged Basins (PUB) initiative of the International association of Hydrological Sciences, and was partially supported by the Italian Government through the CUBIST research project. Much of the analysis was accomplished while the senior author was visiting the Centre for Water Research (CWR), University of Western Australia. We are grateful for the welcome and facilities provided by the CWR. The meteorological and hydrological data were kindly provided by the Australian Bureau of Meteorology (BOM) and the Natural Systems Division of the Department of Infrastructure, Planning and Environment (DIPE), both located in Darwin. Our special thanks go to J. Turnbull (BOM) and D. Chin (DIPE). We are also grateful to J. Samuel for his assistance with the data analysis and the modelling. CWR Reference ED 1545 LM.

Edited by: B. van den Hurk

\section{References}

Atkinson, S. E., Woods, R. A., and Sivapalan, M.: Climate, soil, vegetation controls on water balance model complexity over changing timescales, Water Resour. Res., 38(12), 1314, doi:10.1029/2002WR001487, 2002.

Bathurst, J. C.: Future of distributed modeling: Système Hydrologique Europeén. J. Hydrol., 6, 265-277, 1992.

Begg, G.W., Van Dam, R. A., Lowry, J. B., Finlayson, C. M., and Walden, D. J.: Inventory and risk assessment of water dependent ecosystems in the Daly basin, Northern Territory, Australia, Supervising Scientist Report 162, 1-107, Darwin NT, 2001.

Beven, K. J.: Changing ideas in hydrology: the case of physicallybased models, J. Hydrol., 105, 157-172, 1989.

Beven, K. J.: Towards an alternative blueprint for a physically based digitally simulated hydrologic response modeling system, Hydrol. Proc., 16, 189-206, 2002.

Beven, K. J.: A manifesto for the equifinality thesis, J. Hydrol., 320, 18-36, 2006.

Blöschl, G. and Sivapalan, M.: Scale issues in hydrological modeling: a review, Hydrol. Process., 9(3/4), 251-290, 1995.

Budyko, M. I.: Climate and Life, Academic Press, New York, 1974.

Chiew, F. H. S., Stewardson, M. J., and McMahon, T. A.: Comparison of six rainfall-runoff modelling approaches, J. Hydrol., 147, 1-36, 1993.

Christian, C. S. and Stewart, G. A.: General report on survey of Katherine-Darwin Region, 1946, CSIRO, Australian Land Research Service No. 1, Canberra, 1953.

Eagleson, P. S.: Climate soil, and vegetation, 1: Introduction to water balance dynamics, Water Resour. Res., 14(5), 705-712, 1978.

Farmer, D., Sivapalan, M., and Jothityangkoon, C.: Climate, soil and vegetation controls upon the variability in temperate and semi-arid landscapes: downward approach to hydrological analysis, Water Resour. Res., 39(2), 1035, doi:10.1029/2001WR000328, 2003.

Hutley, L. B., O'Grady, A. P., and Eamus, D.: Evapotranspiration from eucalypt open-forest savanna of northern Australia, Funct. Ecol., 14, 183-194, 2000.

Hutley, L. B., O'Grady, A. P., and Eamus, D.: Monsoonal influences on evapotranspiration of savanna vegetation of northern Australia, Oecol., 126, doi:10.1007/s004420000539, 434-443, 2001.

Jothityangkoon, C., Sivapalan, M., and Farmer, D. L.: Process controls of water balance variability in a large semi-arid catchment: Downward approach to hydrological modeling, J. Hydrol., 254, 174-198, 2001.

Klemes, V.: Conceptualization and scale in hydrology, J. Hydrol., 65, 1-23, 1983.

Manabe, S.: Climate and the ocean circulation, 1, Atmospheric circulation and the hydrology of the Earth's surface, Mon. Weather. Rev., 97(11), 739-774, 1969.

McDonnell, J. J. and Woods, R. A.: On the need for catchment classification, J. Hydrol., 299, 2-3, 2004.

Milly, P. C.: Climate, interseasonal storage of soil water and the annual water balance, Adv. Water Resour., 17, 19-24, 1994a.

Milly, P. C.: Climate, soil water storage, and the average annual water balance, Water Resour. Res., 30(7), 2143-2156, 1994b.

Milly, P. C. and Dunne, K. A.: Sensitivity of the global water cycle to the water holding capacity of land, J. Climate, 7, 506-526, 
1994.

Mulder, C. A. and Whitehead, B. R.: Geology of Katherine Gorge National Park, Report, Geological Survey, Department of Mines and Energy, Darwin, NT, 1988.

Nash, J. E. and Sutcliffe, J. V.: River flow forecasting through conceptual models, 1. A discussion of principles, J. Hydrol., 10, 282-290, 1970.

O'Connell, P. E. and Todini, E.: Modelling of rainfall, flow and mass transport in hydrological systems: an overview, J. Hydrol., 175, 3-16, 1996.

Reggiani, P., Sivapalan, M., and Hassanizadeh, S. M.: A unifying framework for watershed thermodynamics: balance equation for mass, momentum, energy, entropy and the 2nd law of thermodynamics, Adv. in Water Resour., 22(4), 367-398, 1998.

Reggiani, P., Sivapalan, M., and Hassanizadeh, S. M.: Conservation equations governing hillslope responses: Exploring the physical basis of water balance. Water Resour. Res., 36(7), 1845-1864, 2000 .
Sivapalan, M., Takeuchi, K., Franks, S. W., Gupta, V. K., Karambiri, H., Lakshmi, V., Liang, X., McDonnell, J. J., Mendiondo, E. M., O'Connell, P. E., Oki, T., Pomeroy, J. W., Schertzer, D., Uhlenbrook, S., and Zehe, E.: IAHS Decade on Predictions in Ungauged Basins (PUB), 2003-2012: Shaping an exciting future for the hydrological sciences, Hydrol. Sci. J., 48(6), 857-880, 2003a.

Sivapalan, M., Bloschl, G., Zhang, L., and Vertessy, R. A.: Downward approach to hydrological prediction, Hydrol. Process., 17, 2101-2111, doi:10.1002/hyp.1425, 2003b.

Sivapalan, M. and Young, P. C.: Downward approach to hydrological model development, in: Encyclopaedia of Hydrological Sciences, edited by: Anderson, M. G. (Managing Editor), 134, 2098-2801, J. Wiley \& Sons, 2005.

Wittenberg, H. and Sivapalan, M.: Watershed groundwater balance estimation using streamflow recession analysis and baseflow, J. Hydrol., 219, 20-33, 1999. 